\title{
石漠化治理区土地利用变化安全性评价 一以花江、红枫湖、鸭池石漠化治理区为例
}

\author{
罗 娅 $^{1}$, 熊康宁 ${ }^{1}$, 李永圭 ${ }^{2}$, 盈 斌 $^{1}$, 韦清章 $^{3}$
}

(1. 贵州师范大学/国家喀斯特石漠化防治工程技术研究中心, 贵阳 550001;

2. 毕节市科技局, 毕节 $551700 ; 3$. 毕节市防治石漠化管理中心, 毕节 551700$)$

\begin{abstract}
摘要: 土地利用变化的安全性是可持续土地利用的重要评价标准之一。以花江、红枫湖、鸭池 三个石漠化治理区为例,运用“纵横向”拉开档次法,对石漠化治理区土地利用变化的安全性开 展评价, 为评估石漠化治理区土地利用变化效应和改进石漠化治理区的土地利用方式提供借 鉴。结果表明: (1)石漠化治理区的土地利用变化明显。花江、红枫湖、鸭池三个石漠化治理区 的土地利用变化面积比例分别为 $2.85 \% 、 3.34 \%$ 和 $37.88 \%$, 表现为林地和建设用地增加, 耕地和 未利用地减少。(2) 土地利用变化对不同治理区的综合安全性和生态、经济、社会安全性的影响 不同。花江治理区和红枫湖治理区的综合安全性分别提高 $1.44 \%$ 和 $0.46 \%$; 鸭池治理区的综合 安全性下降了 $1.9 \%$ 。花江治理区的生态、社会安全性有所提升,经济安全性有所下降; 红枫湖 治理区的生态安全性有所提升, 经济安全性变化不明显,社会安全性有小幅下降;鸭池治理区 的生态安全性有明显下降,经济安全性有小幅提升,社会安全性有小幅下降。(3)各治理区的生 态、经济、社会安全性对土地利用变化的敏感性存在差异,其中生态安全性对土地利用变化最 敏感。揭示石漠化治理区土地利用变化对生态安全性的影响最明显。在后续石漠化治理和土 地利用规划中,应重点关注土地利用变化对区域生态安全的影响。
\end{abstract}

关键词：安全性;土地利用变化;石漠化;“纵横向”拉开档次法

土地利用变化的安全性是可持续土地利用的重要评价标准之一]. ${ }^{[1]}$ 。土地利用变化会导 致地方和全球的变化, 改变区域提供生态产品和经济产品的安全性, 进而影响区域的社 会安全性 ${ }^{[2]}$ 、生态系统稳定性 ${ }^{[3]}$ 、景观生态安全性 ${ }^{[4]}$ 、地表生物化学循环 ${ }^{\left[{ }^{[}\right]}$、养分循环和小 气候 ${ }^{[6]}$ 、土壤碳储存 ${ }^{[7]}$ 、水资源可获取性 ${ }^{[8]}$ 等等。开展土地利用变化的生态、经济和社会 安全性评价, 认识土地利用变化对区域生态、经济和社会安全性的影响, 可为区域土地 利用变化效应评价及可持续土地利用提供理论参考。

区域土地利用安全性评价应该重点关注社会经济和生态特征的表达 ${ }^{[9]}$ 。当前, 土地利 用安全性评价主要集中在土地利用变化对粮食安全和生态安全的影响方面。Gimona 等 ${ }^{[10]}$ 在苏格兰的研究表明, 林地网络扩张有助于使物种发生扩散距离超过 $2 \mathrm{~km}$ 的栖息地转 变, 但如果快速栖息地转变需要以保护人口生存力为前提, 则这种扩张并不是促进物种

收稿日期：2018-09-05; 修订日期：2018-12-13

基金项目：国家十三五重点研发计划课题（2016YFC0502607）; 贵州省普通高等学校科技拔尖人才支持计划 (黔教合 KY 字[2018]042 号); 贵州师范大学2015 年博士科研启动项目（0514177）

作者简介：罗娅（1979- ), 女，贵州毕节人，教授，研究方向为土地利用与水土流失治理研究。

E-mail: luoya2002@163.com

通讯作者: 熊康宁 (1958- ), 男, 重庆忠县人, 教授, 研究方向为喀斯特地貌与洞穴、喀斯特生态环境 与治理研究。E-mail: xiongkn@163.com 
迁移的灵丹妙药。Zhen 等 ${ }^{[1]}$ 研究了宁夏固原地区的土地利用变化, 认为增加林草覆被而 减少农业用地将会增加粮食短缺的风险。韩冬锐等 ${ }^{[12]}$ 研究长江三角洲城市群热环境安全 格局及土地利用变化，发现建设用地侵占大量耕地也是导致热环境不安全区域扩张的主 要原因。冯异星等 ${ }^{[13]}$ 分析天山北坡玛纳斯河流域的土地利用程度变化, 认为随着土地利 用程度稳定上升, 流域生态安全状况整体有所好转, 但局部生态环境出现恶化趋势。蒙 吉军等 ${ }^{[14}$ 以我国北方农牧交错带的鄂尔多斯市为例, 基于土地利用变化评价该区域安全 性, 结果认为林地的生态安全水平非常稳定, 耕地、建设用地和未利用地最不安全。可 看出, 已有研究多关注同一研究区土地利用变化的单方面影响, 较少同时评估多个研究 区土地利用变化的生态、经济和社会安全性。

石漠化是在喀斯特脆弱生态环境下，人类不合理的社会经济活动，造成人地矛盾突 出、植被破坏、水土流失、岩石逐渐裸露、土地生产力衰退丧失，地表在视觉上呈现类 似于荒漠景观的演变过程 ${ }^{[15]}$ 。中国西南喀斯特地区是世界主要生态脆弱带之一 ${ }^{[16]}$, 石漠 化现象严重, 土地利用活动是影响该区生态系统脆弱性的主要因素 ${ }^{[17]}$ 。近年来, 通过实 施生态修复工程和改变土地利用结构, 石漠化治理区的生态、经济与社会系统发生了明 显的变化。研究表明, 石漠化治理区开展封山育林、退耕还林、坡改梯和小型水利设施 建设后, 会造成喀斯特流域水文系统的响应变化 ${ }^{[18]}$, 提高森林的蓄水保水作用 ${ }^{[19]}$, 调蓄 地表地下径流 ${ }^{[20]}$, 影响土壤有机碳周转速率 ${ }^{[2]}$, 提高生态服务价值 ${ }^{[2]}$ 。但是, 已有研究多 重视石漠化治理对水文系统和土壤环境的影响, 而就石漠化治理区土地利用变化的生 态、经济和社会安全性评价较少, 有待深人开展研究。

综上，在借鉴前人研究的基础上，运用 “纵横向” 拉开档次法，构建土地利用变化 的安全性评价指标体系, 对三个石漠化治理区土地利用变化的安全性开展评价, 为揭示 石漠化治理区的土地利用变化效应提供基础。

\section{1 研究方法与数据来源}

\section{1 研究区概况}

地貌因素是石漠化脆弱生态系统得以存在和发展的物质基础 ${ }^{[23]}$ 。因此, 选择具有不 同地貌特征的毕节鸭池（简称鸭池）、清镇红枫湖（简称红枫湖）、贞丰一关岭花江（简 称花江）三个石漠化治理区为研究区（图 1、表 1)，分别代表喀斯特高原山地、高原盆 地和高原峡谷地貌，开展石漠化治理区小尺度土地利用变化的安全性评价。其中，鸭池 治理区和红枫湖治理区位于长江流域, 花江治理区位于珠江流域。由于三个研究区的石 漠化面积、人口密度、治理时间、治理措施不同，其土地利用变化及安全性也存在差异。

\section{2 研究方法}

运用状态（State）一响应（Response）框架模型，构建评价指标体系后，基于时序 动态视角, 运用 “纵横向” 拉开档次综合评价方法, 开展土地利用变化安全性综合评 价，并分析土地利用变化对生态、经济、社会安全性的影响。

（1）土地利用变化安全性评价指标体系构建思路

恰当的评价指标体系构建是开展土地利用变化安全性评价的基础, 指标确定的方法 主要有特尔斐法和统计分析法两种。其中, 前者适用于资料有限、主要依据专家知识来 


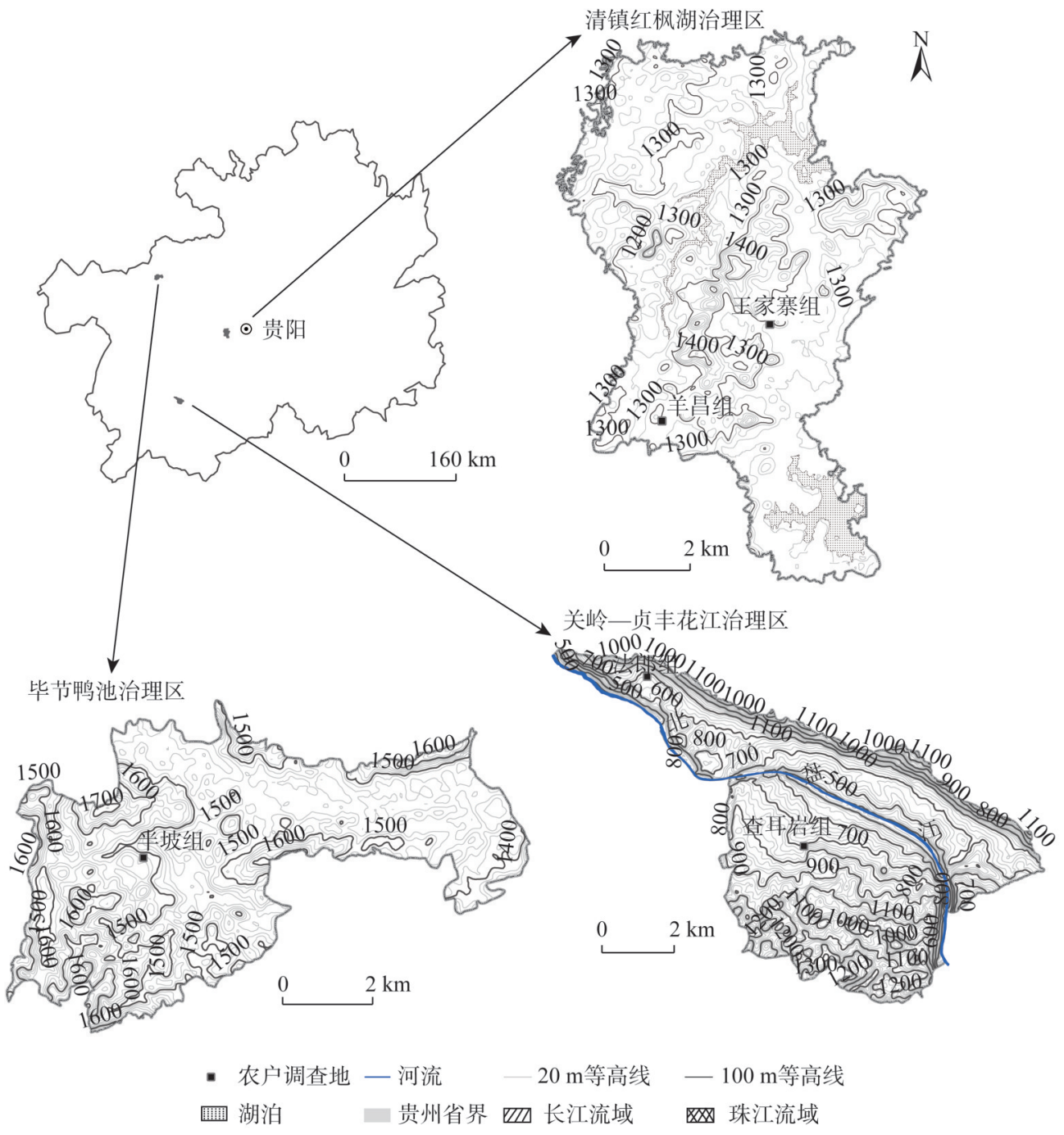

图 1 研究区位置

Fig. 1 Location of the study areas

表 1 研究区概况

Table 1 A survey of study areas

\begin{tabular}{ccccccccc}
\hline \multirow{2}{*}{ 研究区 } & \multirow{2}{*}{ 地貌类型 } & $\begin{array}{c}\text { 海拔 } \\
/ \mathrm{m}\end{array}$ & $\begin{array}{c}\text { 面积 } \\
/ \mathrm{km}^{2}\end{array}$ & $\begin{array}{c}\text { 降雨量 } \\
/ \mathrm{m}\end{array}$ & $\begin{array}{c}\text { 喀斯特面积 } \\
/ \mathrm{km}^{2}\end{array}$ & $\begin{array}{c}\text { 石漠化面积 } \\
/ \mathrm{km}^{2}\end{array}$ & $\begin{array}{c}\text { 人口密度 } \\
/\left(\text { 人 } / \mathrm{km}^{2}\right)\end{array}$ & $\begin{array}{c}\text { 治理起始时 } \\
\text { 间 } / \text { 年 }\end{array}$ \\
\hline 花江 & 高原峡谷 & $446 ~ 1359$ & 51.62 & 1100 & 45.38 & 27.78 & 167 & 1996 \\
红枫湖 & 高原盆地 & $1124 \sim 1438$ & 60.44 & 1200 & 57.65 & 13.10 & 262 & 2001 \\
鸭池 & 高原山地 & $1326 ~ 1721$ & 41.53 & 863 & 26.36 & 9.47 & 513 & 2006 \\
\hline
\end{tabular}

确定指标的被评价对象，后者适用于资料丰富、定量指标易收集的被评价对象 ${ }^{[24]}$ 。由于 研究区较小，统计数据缺乏，资料收集难度大，因此选用特尔斐法确定评价指标。

评估区域的土地利用安全性, 要重点关注区域特有的社会经济和生态特征 ${ }^{[9]}$ 。因此, 选择土地利用安全性指数时有必要考虑石漠化治理区的实际情况。如, 石漠化率和土壤 
侵蚀率是限制土地利用安全性的重要因 素, 在构建指标体系时就需考虑将其作为 评价土地利用安全性的重要指标。运用状 态一响应框架模型, 从指标产生的机理出 发, 以土地利用指标为状态类指标 $(S)$, 以生态安全、经济安全和社会安全为响应 类指标（R）（图 2)。指标体系共有 20 个 指标，其中，状态类有 5 个指标，响应类 (含生态安全响应、经济安全响应和社会安 全响应三个亚类）15个指标（表2）。

(2) 原始数据一致化和无量纲化

为保证不同量纲的指标具有可比性,

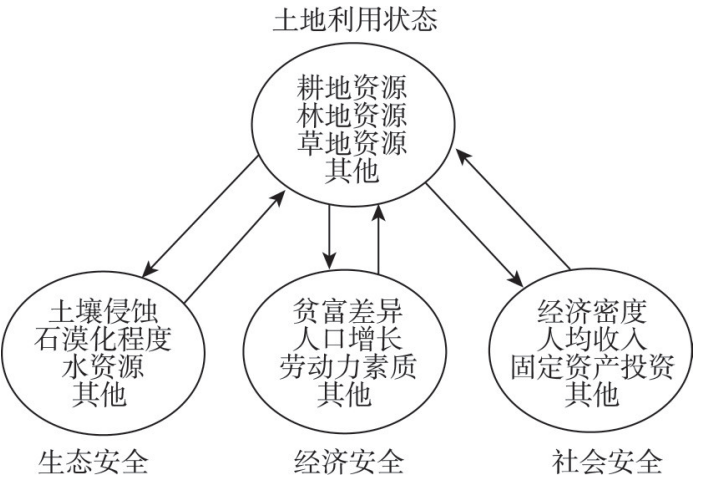

图 2 土地利用变化安全性评价指标体系框架模型

Fig. 2 Framework model on security assessment indicators of land use change

需对原始数据进行一致化和无量纲化两个步骤。数据一致化时, “极大型” 指标不用转 换, 对于 “极小型” 指标 $x$, 令 $x^{*}=\frac{1}{x} \quad(x>0)$, 即转化为 “极大型” 指标。此后, 采用 “标准化” 处理法对一致化了的评价指标无量纲化。

（3）土地利用变化的安全性综合评价

运用具有时序特征的 “纵横向” 拉开档次法 ${ }^{[25]}$, 评价土地利用变化的综合安全性。 该方法既在 “横向”上体现了某一时刻各系统的差异，又在 “纵向”上体现了各系统的

\section{表 2 土地利用变化安全性评价指标体系}

Table 2 The indicator system of security assessment of land use change

\begin{tabular}{|c|c|c|c|c|c|}
\hline 目标层 & 因子层 & 指标层 $(j)$ & 数据来源 & 指标含义 & 权重 \\
\hline 土地利用 & 状态（S） & 人均土地面积/亩 & 遥感调查 & 土地资源人均状态 & 0.00003 \\
\hline 变化的 & 土地利用 & 人均耕地面积/亩 & 遥感调查 & 耕地资源人均状态 & 0.02416 \\
\hline \multirow[t]{18}{*}{ 安全性 } & & 人均草地面积/亩 & 遥感调查 & 草地资源人均状态 & 0.00003 \\
\hline & & 人均林地（园地）面积/亩 & 遥感调查 & 林地（园地）资源人均状态 & 0.00003 \\
\hline & & 水田/旱地比率/\% & 遥感调查 & 耕地结构状态 & 0.08912 \\
\hline & 响应（R）I & 土壤侵蚀面积比例/\% & 遥感调查 & 土壤保持水平响应 & 0.00003 \\
\hline & 生态安全 & 石漠化面积比例/\% & 遥感调查 & 石漠化程度响应 & 0.08396 \\
\hline & & 林灌草覆盖率/\% & 遥感调查 & 植被覆盖度响应 & 0.00003 \\
\hline & & 农业旱灾面积比例/\% & 农户调查 & 农业旱灾响应 & 0.09066 \\
\hline & & 人均水资源 $/ \mathrm{m}^{3}$ & 统计资料 & 水资源人均水平响应 & 0.00003 \\
\hline & 响应（R）II & 经济密度/(元/hm²) & 统计资料 & 土地经济效益响应 & 0.07385 \\
\hline & 经济安全 & 人均地方财政收人/元 & 统计资料 & 地方财政人均水平响应 & 0.07071 \\
\hline & & 农民人均纯收人/元 & 农户调查 & 农民收人水平响应 & 0.05570 \\
\hline & & 人均固定资产投资/元 & 统计资料 & 国定资产投资人均水平响应 & 0.05467 \\
\hline & & 恩格尔系数/\% & 农户调查 & 农民生活水平响应 & 0.07533 \\
\hline & 响应（R）III & 基尼系数（无量纲） & 农户调查 & 贫富差距水平响应 & 0.09051 \\
\hline & 社会安全 & 人口自然增长率/\% & 农户调查 & 人口增长水平响应 & 0.09302 \\
\hline & & 农村贫困发生率/\% & 农户调查 & 当地贫困发生率响应 & 0.09199 \\
\hline & & 富余劳动力转移率/\% & 农户调查 & 富余劳动力转型就业机会响应 & 0.00715 \\
\hline & & 劳动力平均受教育年限/年 & 农户调查 & 劳动力文化水平响应 & 0.09900 \\
\hline
\end{tabular}


总体情况，能够解决基于时序的多指标决策问题 ${ }^{[26]}$ 。

根据 “纵横向” 拉开档次动态综合评价方法，对于时刻 $t_{k},\left(t_{k}=2005,2012\right)$, 取 综合评价函数为:

$$
y_{i}^{*}\left(t_{k}\right)=\sum_{j=1}^{m} w_{j} x_{i j}\left(t_{k}\right) \quad(i=1,2,3 ; m=20)
$$

式中： $i$ 为研究区代码; $m$ 代表指标数量; $y_{i}^{*}\left(t_{k}\right)$ 代表研究区 $i$ 在时刻 $t_{k}$ 的综合评价值, 无量纲; $x_{i j}\left(t_{k}\right)$ 为 $i$ 研究区 $j$ 指标在时刻 $t_{k}$ 的无量纲值; $w_{j}$ 为指标 $j$ 的权重。20个单项 指标的权重系数计算结果见表 2 。

通过式（1）可求出三个研究区在 2005 年、2012 年土地利用安全性综合评价值，无 量纲。显然, $y_{i}\left(t_{k}\right)$ 的值越大越好。为便于直观比较, 又不失一般性, 将 $y_{i}^{*}\left(t_{k}\right)$ 作平移、 放大处理，即取:

$$
y_{i}\left(t_{k}\right)=\left(y_{i}^{*}\left(t_{k}\right)+6\right) \times 10 \quad\left(i=1,2,3 ; t_{k}=2005,2012\right)
$$

(4) 土地利用变化的生态、经济、社会安全性评价

运用式（3）和式（4)，求出三个研究区在 2005 年、2012年的生态安全评价值。

$$
\begin{gathered}
E y_{i}^{*}\left(t_{k}\right)=\sum_{j=6}^{10} w_{j} x_{i j}\left(t_{k}\right) \quad\left(i=1,2,3 ; t_{k}=2005,2012\right) \\
E y_{i}\left(t_{k}\right)=\left(E y_{i}^{*}\left(t_{k}\right)+6\right) \times 10 \quad\left(i=1,2,3 ; t_{k}=2005,2012\right)
\end{gathered}
$$

式中： $E y_{i}^{*}\left(t_{k}\right)$ 代表研究区 $i$ 在时刻 $t_{k}$ 的生态安全评价值，无量纲； $j$ 表示表 2 中的第 $6 \sim$ 10 项指标; $E y_{i}\left(t_{k}\right)$ 是将 $E y_{i}^{*}\left(t_{k}\right)$ 作平移、放大处理后的生态安全评价值，无量纲。

运用式（5）和式（6），求出三个治理区在 2005 年、2012年的经济安全评价值。

$$
\begin{gathered}
F y_{i}^{*}\left(t_{k}\right)=\sum_{j=11}^{15} w_{j} x_{i j}\left(t_{k}\right) \quad\left(i=1,2,3 ; t_{k}=2005,2012\right) \\
F y_{i}\left(t_{k}\right)=\left(F y_{i}^{*}\left(t_{k}\right)+6\right) \times 10 \quad\left(i=1,2,3 ; t_{k}=2005,2012\right)
\end{gathered}
$$

式中: $F y_{i}^{*}\left(t_{k}\right)$ 代表研究区 $i$ 在时刻 $t_{k}$ 的经济安全评价值，无量纲； $j$ 表示表 2 中的第 $11 \sim$ 15 项指标; $F y_{i}\left(t_{k}\right)$ 是将 $F y_{i}^{*}\left(t_{k}\right)$ 作平移、放大处理后的经济安全评价值，无量纲。

运用式（7）和式（8)，求出三个治理区在 2005 年、2012 年的社会安全评价值。

$$
\begin{gathered}
S y_{i}^{*}\left(t_{k}\right)=\sum_{j=16}^{20} w_{j} x_{i j}\left(t_{k}\right) \quad(i=1,2,3) \\
S y_{i}\left(t_{k}\right)=\left(S y_{i}^{*}\left(t_{k}\right)+6\right) \times 10 \quad\left(i=1,2,3 ; t_{k}=2005,2012\right)
\end{gathered}
$$

式中： $S y_{i}^{*}\left(t_{k}\right)$ 代表研究区 $i$ 在时刻 $t_{k}$ 的社会安全评价值，无量纲； $j$ 表示表 2 中的第 16 20 项指标; $S y_{i}\left(t_{k}\right)$ 是将 $S y_{i}^{*}\left(t_{k}\right)$ 作平移、放大处理后的社会安全评价值，无量纲。

（5）生态、经济、社会安全性变化对土地利用变化的敏感性分析

构建土地一生态弹性系数（ $E K)$ 、土地一经济弹性系数（FK）、土地一社会弹性 系数 $(S K)$ ，揭示生态、经济、社会各系统安全性对土地利用变化的敏感性，反映土地 利用变化对生态、经济、社会系统的影响。首先, 运用式 (9) 和式 (10), 计算三个研 究区在 2005 年、2012年的土地利用状态值。

$$
L y_{i}^{*}\left(t_{k}\right)=\sum_{j=1}^{5} w_{j} x_{i j}\left(t_{k}\right) \quad\left(i=1,2,3 ; t_{k}=2005,2012\right)
$$




$$
L y_{i}\left(t_{k}\right)=\left(L y_{i}^{*}\left(t_{k}\right)+6\right) \times 10 \quad\left(i=1,2,3 ; t_{k}=2005,2012\right)
$$

式中： $L y_{i}^{*}\left(t_{k}\right)$ 代表研究区 $i$ 在时刻 $t_{k}$ 的土地利用状态值; $j$ 表示表 2 中的第 1 5 项指标; $L y_{i}\left(t_{k}\right)$ 是将 $L y_{i}^{*}\left(t_{k}\right)$ 作平移、放大处理后的土地利用状态值。

其次，运用式（11）～式（13），构建土地一生态弹性系数（ $E K)$ 、土地一经济弹性 系数 $(F K)$ 、土地一社会弹性系数 $(S K)$ 。弹性系数可能为正值, 也可能为负值, 为便 于比较各研究区情况, 取其绝对值作为分析依据。

$$
E K=\left|\frac{\frac{E y_{i}\left(t_{2012}\right)-E y_{i}\left(t_{2005}\right)}{E y_{i}\left(t_{2005}\right)}}{\frac{L y_{i}\left(t_{2012}\right)-L y_{i}\left(t_{2005}\right)}{L y_{i}\left(t_{2005}\right)}}\right| \quad(i=1,2,3)
$$

式中: $E y_{i}\left(t_{2005}\right) 、 E y_{i}\left(t_{2012}\right)$ 分别指研究区 $i$ 在 2005 年、2012 年的生态安全评价值; $L y_{i}\left(t_{2005}\right) 、 L y_{i}\left(t_{2012}\right)$ 分别指研究区 $i$ 在 2005 年、2012 年的土地利用状态值; $E K$ 是土地一 生态弹性系数。 $E K$ 值越大，揭示生态安全性对土地利用变化越敏感，表明土地利用变 化对生态安全性的影响越大。

$$
F K=\left|\frac{\frac{F y_{i}\left(t_{2012}\right)-F y_{i}\left(t_{2005}\right)}{F y_{i}\left(t_{2005}\right)}}{\frac{L y_{i}\left(t_{2012}\right)-L y_{i}\left(t_{2005}\right)}{L y_{i}\left(t_{2005}\right)}}\right| \quad(i=1,2,3)
$$

式中: $F y_{i}\left(t_{2005}\right) 、 F y_{i}\left(t_{2012}\right)$ 分别指研究区 $i$ 在 2005 年、2012 年的经济安全评价值; $L y_{i}\left(t_{2005}\right) 、 L y_{i}\left(t_{2012}\right)$ 分别指研究区 $i$ 在 2005 年、2012 年的土地利用状态值; $F K$ 是土地一 经济弹性系数。FK 值越大, 揭示经济安全性对土地利用变化越敏感, 表明土地利用变 化对经济安全性的影响越大。

$$
S K=\left|\frac{\frac{S y_{i}\left(t_{2012}\right)-S y_{i}\left(t_{2005}\right)}{S y_{i}\left(t_{2005}\right)}}{\frac{L y_{i}\left(t_{2012}\right)-L y_{i}\left(t_{2005}\right)}{L y_{i}\left(t_{2005}\right)}}\right| \quad(i=1,2,3)
$$

式中： $S y_{i}\left(t_{2005}\right) 、 S y_{i}\left(t_{2012}\right)$ 分别指研究区 $i$ 在 2005 年、2012 年的社会安全评价值; $L y_{i}\left(t_{2005}\right) 、 L y_{i}\left(t_{2012}\right)$ 分别指研究区 $i$ 在 2005 年、2012 年的土地利用状态值; $S K$ 是土地一 社会弹性系数。SK 值越大, 揭示社会安全性对土地利用变化越敏感, 表明土地利用变 化对社会安全性的影响越大。

\section{3 数据来源}

遥感数据：选用SPOT 5 遥感影像作为遥感数据源，结合研究区的地质图，用于提取 研究地喀斯特区的土地利用信息。由于研究区的云、雾天气多，难以获取其2005 年、 2012 年的高质量遥感图像，且 2004 年与 2005 年、2012 年与 2013 年的土地利用变化不明 显。因此，2005 年、2012 年的土地利用数据选用与之年份相邻的 2004 年 12 月 15 日与 2013 年 5 月 6 日的遥感数据作为数据源。对遥感数据进行直方图匹配、几何校正、图像

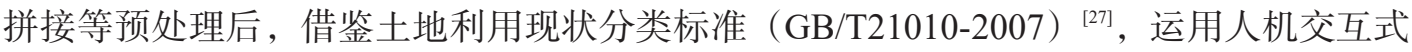
解译方法, 将土地利用现状分为耕地、林地、园地、草地、水域、建设用地和未利用地 7 种类型，获取研究区 2005 年、2012年的土地利用数据。需特别说明的是，花江的石漠 
化治理以花椒种植为主, 之后又开展了火龙果种植, 因此将花椒和火龙果种植地都划分 为园地类型 ${ }^{[28]}$ 。

统计资料：人均固定资产投资、人均财政收人和人均水资源三个指标主要由地方经 济与资源水平决定，通过研究区所在县级行政单元的统计年鉴数据计算获取。此外，经 济密度指标来源于实地村（组）社会经济普查。其中，在花江治理区普查了9村 52 个村 民组，在红枫湖治理区普查了 10 村 67 个村民组，在鸭池治理区普查了 10 村 104 个村民组。

农户调查：分别于 2006 年 1 月和 2013 年 1 月对典型农户开展问卷调查，分别获取 2005 年和 2012 年的农民人均纯收人、人口自然增长率、富余劳动力转移率等指标。根据 三个治理区的人口分布状况，在花江治理区的法郎社区和查尔岩社区调查了 90 户农户， 在红枫湖治理区的羊昌洞社区和王家寨社区调查了93户农户，在鸭池治理区的半坡社区 调查了96户农户。典型农户调查地分布见图 1 。

\section{2 结果分析}

\section{1 石漠化治理区土地利用变化概况}

统计各治理区 2005 年、2012 年的地类面积，可看出其2005-2012年的土地利用变化 情况（表3, 图 3):

（1）花江治理区 土地利用变化面积比例为 $2.85 \%$ ，表现为水域、建设用地和未利 用地增加，耕地、园地、林地和草地减少。其中，水域增加面积最大 $\left(+42.81 \mathrm{hm}^{2}\right)$ (系下游筑坝拦水所致), 建设用地增加面积次之 $\left(+18.53 \mathrm{hm}^{2}\right)$, 未利用地增加面积最 小 $\left(+10.57 \mathrm{hm}^{2}\right)$; 园地减少面积最大 $\left(-48.01 \mathrm{hm}^{2}\right)$, 耕地减少面积次之 $\left(-10.74 \mathrm{hm}^{2}\right)$, 林地减少面积排第三位 $\left(-9.55 \mathrm{hm}^{2}\right)$ ，草地减少面积最少 $\left(-3.61 \mathrm{hm}^{2}\right)$ 。

（2）红枫湖治理区 土地利用变化面积比例为 $3.34 \%$ ，表现为园地、林地、草地和建 设用地增加，耕地、水域和未利用地减少。其中，林地增加面积最大 $\left(+73.74 \mathrm{hm}^{2}\right)$, 建 设用地增加面积次之 $\left(+14.55 \mathrm{hm}^{2}\right)$, 园地增加面积排第三位 $\left(+10.21 \mathrm{hm}^{2}\right)$, 草地增加面 积最小 $\left(+0.84 \mathrm{hm}^{2}\right)$; 未利用地减少面积最大 $\left(-71.26 \mathrm{hm}^{2}\right)$, 耕地减少面积次之 $\left(-25.09 \mathrm{hm}^{2}\right)$, 水域减少面积最小 $\left(-2.99 \mathrm{hm}^{2}\right)$ 。

（3）鸭池治理区 土地利用变化面积比例为 $37.88 \%$, 表现为园地、林地、草地、水

表 $32005-2012$ 年研究区土地利用变化

Table 3 Land use change of study areas in 2005 and 2012

\begin{tabular}{|c|c|c|c|c|c|c|c|c|c|}
\hline \multirow[b]{2}{*}{ 地类 } & \multicolumn{3}{|c|}{ 花江 } & \multicolumn{3}{|c|}{ 红枫湖 } & \multicolumn{3}{|c|}{ 鸭池 } \\
\hline & 2005 年 & 2012年 & $\begin{array}{c}2012 \text { 年比 } \\
2005 \text { 年(+/-) }\end{array}$ & 2005 年 & 2012年 & $\begin{array}{c}2012 \text { 年比 } \\
2005 \text { 年(+/-) }\end{array}$ & 2005 年 & 2012年 & $\begin{array}{c}2012 \text { 年比 } \\
2005 \text { 年(+/-) }\end{array}$ \\
\hline 耕地 & 717.46 & 706.72 & -10.74 & 3126.82 & 3101.73 & -25.09 & 1492.88 & 1370.89 & -121.99 \\
\hline 园地 & 899.38 & 851.37 & -48.01 & 25.09 & 35.30 & 10.21 & 0.39 & 5.41 & 5.02 \\
\hline 林地 & 1705.57 & 1696.02 & -9.55 & 1370.65 & 1444.39 & 73.74 & 785.75 & 806.86 & 21.11 \\
\hline 草地 & 297.19 & 293.58 & -3.61 & 318.74 & 319.58 & 0.84 & 14.39 & 14.58 & 0.19 \\
\hline 水域 & 74.39 & 117.20 & 42.81 & 461.38 & 458.39 & -2.99 & 18.18 & 18.59 & 0.41 \\
\hline 建设用地 & 71.21 & 89.74 & 18.53 & 188.42 & 202.97 & 14.55 & 202.97 & 309.76 & 106.79 \\
\hline 未利用地 & 773.23 & 783.80 & 10.57 & 274.38 & 203.12 & -71.26 & 121.01 & 109.48 & -11.53 \\
\hline 合计 & 4538.43 & 4538.43 & / & 5765.48 & 5765.48 & / & 2635.57 & 2635.57 & I \\
\hline
\end{tabular}



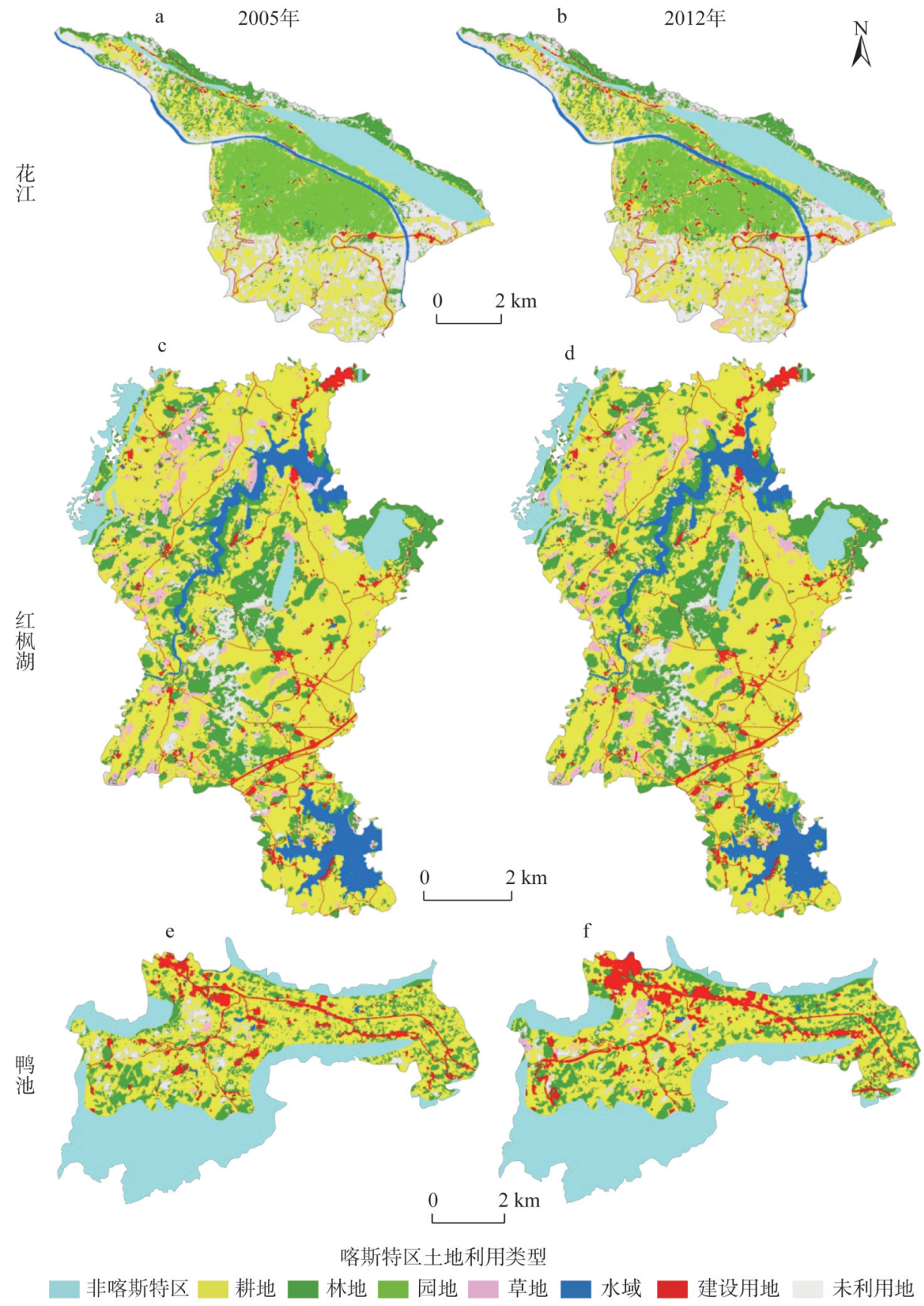

图32005年、2012年研究区土地利用图

Fig. 3 Land use of the study areas in 2005 and 2012

域和建设用地增加，耕地和未利用地减少。其中，建设用地增加面积最大 $\left(+106.79 \mathrm{hm}^{2}\right)$ ，林地增加面积次之 $\left(+21.11 \mathrm{hm}^{2}\right)$ ，园地增加面积排第三位 $\left(+5.02 \mathrm{hm}^{2}\right)$, 草地和水域增加面积均较小; 耕地减少面积最大 $\left(-121.99 \mathrm{hm}^{2}\right)$, 未利用 地减少面积最小 $\left(-11.53 \mathrm{hm}^{2}\right)$ 。

结果表明，石漠化治理区土地利用变化明显，若不考虑大型筑坝拦水工程建设的原 
因，总体表现为林地和建设用地增加，耕地和未利用地减少的趋势。

\section{2 土地利用变化的安全性综合评价}

运用式（1）和式 (2)，计算出各研究区土地利用变化安全性综合值。从表 4 可看 出, 无论是 2005 年还是 2012 年, 三个治理区土地利用的安全性都呈现红枫湖 $>$ 甲鸟池 $>$ 花 江的趋势。此外，从 2005 年、2012年各治理区的安全性综合评价值变化看，花江、红枫 湖两个治理区略有上升，前者的安全性综合评价值从53.37 提高到 54.14（提高了 $1.44 \%$ ），后者的安全性综合评价值从 69.28 提高到 69.60 （提高了 $0.46 \%$ ）；鸭池治理区有 明显下降，其安全性综合评价值从 57.35 下降到 56.26 ，下降了 $1.9 \%$ 。

结果表明，伴随土地利用变化，花江 治理区和红枫湖治理区的综合安全性有所 提高, 鸭池治理区的综合安全性有所下降。

表 42005 年、 2012 年研究区安全性综合评价值

Table 4 Comprehensive security assessment values of study areas in 2005 and 2012

\section{3 土地利用变化的生态、经济、社会安全性}

运用式（3）～式（8），评价各研究区 生态、经济、社会各系统安全性变化。从 表 5 可看出，花江治理区的生态安全性评价

\begin{tabular}{cccc}
\hline 年份 & 花江 & 红枫湖 & 鸭池 \\
\hline 2005 & 53.37 & 69.28 & 57.35 \\
2012 & 54.14 & 69.60 & 56.26 \\
\hline
\end{tabular}
值从 57.99 提高到 58.51 , 提高了 $0.90 \%$; 经济安全性评价值从 58.67 降低到 58.45 , 下降了 $0.38 \%$ ；社会安全性评价值从 57.22 提高到 57.45 ，提高了 $0.41 \%$ 。红枫湖治理区的生态安 全性评价值从 61.05 提高到 61.59 ，提高了 $0.89 \%$ ；经济安全性评价值从 62.78 提高到 62.83 ，提高了 $0.07 \%$ ；社会安全性评价值从 64.17 降低到 64.09 ，下降了 $0.13 \%$ 。鸭池治理 区的生态安全性评价值从 60.97 降低到 59.90 ，下降了 $1.75 \%$ ；经济安全性评价值从 58.54 提高到 58.72 , 提高了 $0.31 \%$; 社会安全性评价值从 58.61 降低到 58.46 , 下降了 $0.26 \%$ 。

结果表明，土地利用变化后，花江治理区的生态安全性和社会安全性有所提升，经 济安全性有所下降; 红枫湖治理区的生态安全性有所提升, 经济安全性变化不明显, 社 会安全性有小幅下降；鸭池治理区的生态安全性有明显下降，经济安全性有小幅提升， 社会安全性有小幅下降。

\section{4 生态、经济、社会安全性对土地利用变化的敏感性}

通过式（9）～式（13），计算出三个研究区的土地一生态弹性系数（EK）、土地一 经济弹性系数 $(F K)$ 和土地-社会弹性系数 $(S K)$ 。从表 6 可看出, 各研究区 $E K$ 、 $F K 、 S K$ 的大小顺序排列为：花江治理区呈现 $E K \quad(2.27)>S K （ 1.05 ）>(0.96) F K$ 趋势, 红枫湖治理区呈现 $E K \quad(3.85)>S K \quad(0.21)>F K \quad(0.11)$ 趋势, 鸭池治理区呈 现 $E K \quad(21.65)>F K \quad(3.82)>S K \quad(3.24)$ 趋势。

结果发现，三个研究区中，鸭池治理区生态、经济、社会安全性对土地利用变化最

表 52005 年、2012 年研究区生态、经济、社会安全性评价值

Table 5 Ecological, economic and social security assessment values of study areas in 2005 and 2012

\begin{tabular}{|c|c|c|c|c|c|c|}
\hline \multirow{2}{*}{ 研究区 } & \multicolumn{2}{|c|}{ 生态安全 } & \multicolumn{2}{|c|}{ 经济安全 } & \multicolumn{2}{|c|}{ 社会安全 } \\
\hline & 2005 年 & 2012年 & 2005 年 & 2012年 & 2005 年 & 2012年 \\
\hline 花江 & 57.99 & 58.51 & 58.67 & 58.45 & 57.22 & 57.45 \\
\hline 红枫湖 & 61.05 & 61.59 & 62.78 & 62.83 & 64.17 & 64.09 \\
\hline 鸭池 & 60.97 & 59.90 & 58.54 & 58.72 & 58.61 & 58.46 \\
\hline
\end{tabular}


为敏感，表明土地利用变化对其生态、经

表 6 研究区 $E K 、 F K 、 S K$ 值

济、社会安全性影响最大。三个研究区均 呈现生态安全性较经济、社会安全性对土 地利用变化最为敏感的特征, 表明各治理 区土地利用变化对生态安全性影响最明显。

Table $6 E K, F K, S K$ values of study areas

\begin{tabular}{lccc}
\hline 研究区 & $E K$ & $F K$ & $S K$ \\
\hline 花江 & 2.27 & 0.96 & 1.05 \\
红枫湖 & 3.85 & 0.11 & 0.21 \\
鸭池 & 21.65 & 3.82 & 3.24 \\
\hline
\end{tabular}

\section{3 结论与讨论}

\section{1 结论}

基于时序动态视角，运用 “纵横向” 拉开档次综合评价方法，对三个石漠化治理区 开展土地利用变化安全性综合评价，并分析土地利用变化对生态、经济、社会安全性的 分别影响。结果表明:

（1）石漠化治理区的土地利用变化明显。花江、红枫湖和鸭池三个石漠化治理区的 土地利用变化面积比例分别为 $2.85 \% 、 3.34 \%$ 和 $37.88 \%$ 。若不考虑大型筑坝拦水工程建设 的影响，总体表现为林地和建设用地增加，耕地和未利用地减少的趋势。

（2）土地利用变化对不同治理区的综合安全性和生态、经济、社会安全性的影响不 同。花江治理区和红枫湖治理区的综合安全性有所提高，分别提高了 $1.44 \%$ 和 $0.46 \%$; 鸭 池治理区的综合安全性有所下降，下降了 $1.9 \%$ 。就各治理区的生态、经济、社会各子系 统安全性变化而言，花江治理区的生态安全性和社会安全性有所提升，经济安全性有所 下降; 红枫湖治理区的生态安全性有所提升, 经济安全性变化不明显, 社会安全性有小 幅下降; 鸭池治理区的生态安全性有明显下降，经济安全性有小幅提升，社会安全性有 小幅下降。

（3）各治理区的生态、经济、社会安全性对土地利用变化的敏感性差异明显，其中 生态安全性对土地利用变化最为敏感。三个治理区均呈现土地一生态弹性系数（EK） 最大的特征, 表明各区的生态安全性较经济、社会安全性对土地利用变化较为敏感。揭 示出石漠化治理区土地利用变化对生态安全性的影响最明显。在后续石漠化治理和土地 利用规划中，应重点关注土地利用变化对区域生态安全的影响。此外还发现，鸭池治理 区的生态、经济、社会安全性对土地利用变化最为敏感，其土地一生态弹性系数 $(E K)$ 、土地一经济弹性系数 $(F K)$ 和土地一社会弹性系数 $(S K)$ 分别为 $21.65 、 3.82$ 和 3.24, 均比花江治理区和红枫湖治理区的同类指标值大，表明土地利用变化对鸭池治 理区的生态、经济、社会安全性的影响最大。

\section{2 讨论}

开展石漠化治理区土地利用变化的安全性评价，有助于揭示该区域的土地利用变化 效应, 从而为改进其土地利用方式提供参考。本研究与已有成果 ${ }^{[14,17,29]}$ 相比有如下区别: （1）构建评价指标体系时，针对石漠化治理区的实际，运用状态一响应框架模型，从指 标产生的机理出发, 以土地利用指标为状态类指标，以生态安全、经济安全和社会安全 为响应类指标，不仅关注土地利用变化的生态安全性，而且还重视土地利用变化的经济 安全性和社会安全性，从而强调土地利用变化对生态、经济和社会安全性的综合影响。 （2）运用 “纵横向” 拉开档次综合评价方法, 无论对于 “横向截面” 数据, 还是对于 “纵向时序立体数据”, 其综合评价结果都具有可比性。这样, 既在 “横向” 上体现了某 
一时刻不同治理区的土地利用变化安全性区别，又能在 “纵向”上反映出同一治理区不 同时刻的土地利用变化安全性差异，为揭示不同石漠化治理区土地利用变化效应提供新 思路。（3）此外，通过构建土地一生态弹性系数（ $E K ）$ 、土地一经济弹性系数（FK） 和土地一社会弹性系数（ $S K)$ ，分析石漠化治理区生态、经济、社会安全性对土地利用 变化的敏感性, 揭示土地利用变化对生态、经济、社会安全性的影响大小, 为改进石漠 化治理区的土地利用方式提供重要参考。

\section{参考文献(References):}

[1] FAO. FESLM: An International Framework for Evaluation Sustainable Land Management. Rome: World Soil Resources Report 73, 1993: 12-80.

[2] 刘彦随. 保障我国土地资源安全的若干战略思考. 中国科学院院刊, 2006, 21(5): 379-384. [LIU Y S. Strategies to guarantee land resources safety in China. Bulletin of Chinese Academy of Sciences, 2006, 21(5): 379-384.]

[3] LI Y, SUN X, ZHU X, et al. An early warning method of landscape ecological security in rapid urbanizing coastal areas and its application in Xiamen, China. Ecological Modelling, 2010, 221: 2251-2260.

[4] ZHANG R S, PU L J, LI J G, et al. Landscape ecological security response to land use change in the tidal flat reclamation zone, China. Environmental Monitoring and Assessment, 2016, 188: 1-10.

[5] LAMBIN E F, EHRLICH D. Land-cover changes in sub-Saharan Africa (1982-1991): Application of a change index based on remotely sensed surface temperature and vegetation indices at a continental scale. Remote Sensing of Environment, 1997, 61: 181-200.

[6] LI R Q, DONG M, CUI J Y, et al. Quantification of the impact of land-use changes on ecosystem services: A case study in Pingbian county, China. Environmental Monitoring and Assessment, 2007, 128: 503-510.

[7] COLLARD S J, ZAMMIT C. Effects of land-use intensification on soil carbon and ecosystem services in Brigalow (Acacia harpophylla) landscapes of Southeast Queensland, Australia. Agriculture, Ecosystems and Environment, 2006, 117: 185-194.

[8] FIQUEPRON J, GARCIA S, STENGER A. Land use impact on water quality: Valuing forest services in terms of the water supply sector. Journal of Environmental Management, 2013, 126: 113-121.

[9] LING H B, XU H L, FU J Y. Evaluation of oasis land use security and sustainable utilization strategies in a typical watershed in the arid regions of China. Environmental Earth Sciences, 2013, 70: 2225-2235.

[10] GIMONA A, POGGIO L, POLHILl G J, et al. Habitat networks and food security: Promoting species range shift under climate change depends on life history and the dynamics of land use choices. Landscape Ecology, 2015, 30: 771-789.

[11] ZHEN L, DENG X Z, WEI Y J, et al. Future land use and food security scenarios for the Guyuan district of remote Western China. Iforest-Biogeosciences \& Forestry, 2014, 7: 372-384.

[12] 韩冬锐, 徐新良, 李静, 等. 长江三角洲城市群热环境安全格局及土地利用变化影响研究. 地球信息科学学报, 2017, 19(1): 39-49. [HAN D R, XU X L, LI J, et al. Study on the security pattern of the heat environment and the influence of land use change in the Yangtze River Delta urban agglomeration. Journal of Geo-Information Science, 2017, 19(1): 3949.]

[13] 冯异星, 罗格平, 尹昌应, 等. 干旱区内陆河流域土地利用程度变化与生态安全评价: 以新疆玛纳斯河流域为例. 自 然资源学报, 2009, 24(11): 1921-1932. [FENG Y X, LUO G P, YIN C Y, et al. Change of land-use degree and ecological security assessment of inland river basins in the arid area: A case study of Manas River Basin in Xinjiang. Journal of Natural Resources, 2009, 24(11): 1921-1932.]

[14] 蒙吉军, 赵春红, 刘明达. 基于土地利用变化的区域生态安全评价: 以鄂尔多斯市为例. 自然资源学报, 2011, 26(4): 578-590. [MENG J J, ZHAO C H, LIU M D. Regional ecological security assessment based on land-use change: A case study in Ordos city. Journal of Natural Resources, 2011, 26(4): 578-590.]

[15] 熊康宁, 黎平, 周忠发, 等. 喀斯特石漠化的遥感 - GIS 典型研究: 以贵州省为例. 北京: 地质出版社, 2002. [XIONG K N, LI P, ZHOU Z F, et al. The RS and GIS Representative Study on Karst Rock Desertification: An Example of Guizhou Province. Beijing: Geology Press, 2002.] 
[16] 袁道先. 全球岩溶生态系统对比: 科学目标和执行计划. 地球科学进展, 2001, 16(4): 461-466. [YUAN D X. World correlation of karst ecosystem: Objectives and implementation plan. Advances in Earth Science, 2001, 16(4): 461-466.]

[17] ZHAO H J, MA F S, GUO J. Regularity and formation mechanism of large-scale abrupt karst collapse in Southern China in the first half of 2010. Natural Hazards, 2012, 60(3): 1037-1054.

[18] 戴明宏, 张军以, 王腊春, 等. 岩溶地区土地利用/覆被变化的水文效应研究进展. 生态科学, 2015, 34(3): 189-196. [DAI M H, ZHANG J Y, WANG L C, et al. A review on impacts of land use/land cover change on water resources in Karst areas. Ecological Science, 2015, 34(3): 189-196.]

[19] 赵宇变, 葛玉娟, 旷成华, 等. 乡村振兴战略下贵州山区森林转型路径研究. 贵州师范大学学报: 自然科学版, 2018, 36(1): 1-6. [ZHAO Y L, GE Y J, KUANG C H, et al. The path of forest transformation in mountainous areas in Guizhou province under the strategy of rural revitalization. Journal of Guizhou Normal University: Natural Sciences, 2018, 36 (1): 1-6.]

[20] TRCEK B, VESELIC M, PEZDIC J. The vulnerability of Karst springs: A case study of the Hubelj spring (SW Slovenia). Environmental Geology, 2006, 49(6): 865-874.

[21] 张文娟, 廖洪凯, 龙健, 等. 贵州喀斯特山区土地利用对土壤有机碳及其周转速率的影响. 生态学杂志, 2014, 33(5): 1297-1303. [ZHANG W J, LIAO H K, LONG J, et al. Effects of land use on soil organic carbon and its turnover rate in Karst mountain areas of Guizhou province. Chinese Journal of Ecology, 2014, 33(5): 1297-1303.]

[22] 罗光杰, 王世杰, 李阳兵, 等. 岩溶地区坡耕地时空动态变化及其生态服务功能评估. 农业工程学报, 2014, 30(11): 233-243. [LUO G J, WANG S J, LI Y B, et al. Spatio-temporal dynamics and ecological service function assessment of slope farmland in Karst areas of Guizhou province, China. Transactions of the CSAE, 2014, 30(11): 233-243.]

[23] 曹建华, 袁道先, 童立强. 中国西南岩溶生态系统特征与石漠化综合治理对策. 草业科学, 2008, 25(9): 40-50. [CAO J H, YUAN D X, TONG L Q. Features of Karst ecosystem and integrating measure for rock desertification in Southwest China. Pratacultural Science, 2008, 25(9): 40-50.]

[24] 邵立周, 白春杰. 系统综合评价指标体系构建方法研究. 海军工程大学学报, 2008, 20(3): 48-52. [SHAO L Z, BAI C J. Index system construction on comprehensive evaluation. Journal of Naval University of Engineering, 2008, 20(3): 4852.]

[25] 郭亚军. 一种新的动态综合评价方法. 管理科学学报, 2002, 5(2): 49-54. [GUO Y J. New theory and method of dynamic comprehensive evaluation. Journal of Management Sciences in China, 2002, 5(2): 49-54.]

[26] 陈国红, 康艺苹, 李美娟. 区域科技创新能力动态评价: 基于改进的“纵横向”拉开档次评价法. 技术经济, 2015, 34 (10): 17-23. [CHEN G H, KANG Y P, LI M J. Dynamic evaluation on regional scientific and technological innovation capability: Based on improved vertical and horizontal evaluation method. Technology Economics, 2015, 34(10): 17-23.]

[27] 国家质量监督检验检疫总局. 中国国家标准管理委员会. 土地利用现状分类. 中华人民共和国国家标准 (GB/ T21010-2007). 北京: 中国标准出版社, 2007. [Standardization Administration of the People's Republic of China. Current land use condition classification. China's National Standard (GB/T21010-2007). Beijing: Standards Press of China, 2007.]

[28] 彭睿文, 罗娅, 陈起伟, 等. 石漠化治理区小尺度土地利用变化及其驱动机制分析: 以花江石漠化治理区为例. 长江 流域资源与环境, 2017, 26(12): 2072-2081. [PENG R W, LUO Y, CHEN Q W, et al. Land use change and its driving mechanism in small-scale rocky desertification control area: Take the Huajiang rocky desertification control area as an example. Resources and Environment in the Yangtze Basin, 2017, 26(12): 2072-2081.]

[29] 李成志, 连晋姣, 陈洪松, 等. 喀斯特地区县域土壤侵蚀估算及其对土地利用变化的响应. 中国水土保持科学, 2017, 15(5): 39-47. [LI C Z, LIAN J J, CHEN H S, et al. Estimation of soil erosion and its response to land use change in Karst regions at county scale. Science of Soil and Water Conservation, 2017, 15(5): 39-47.] 


\title{
Evaluation on security of land use change in rocky desertification control areas: Taking Huajiang, Hongfenghu and Yachi as examples
}

\author{
LUO Ya ${ }^{1}$, XIONG Kang-ning ${ }^{1}$, LI Yong-yao ${ }^{2}$, YING Bin $^{1}$, WEI Qing-zhang ${ }^{3}$ \\ (1. Guizhou Normal University/State Engineering Technology Institute for Karst Desertification Control, \\ Guiyang 550001, China; 2. Bijie Science and Technology Bureau, Bijie 551700, Guizhou, China; 3. Bijie \\ Management Center for Rocky Desertification Control, Bijie 551700, Guizhou, China )
}

\begin{abstract}
The security of land use change is one of the important criteria for evaluating sustainable land use. The study takes Huajiang, Hongfenghu and Yachi rocky desertification control areas as examples, evaluates the security of land use change of rocky desertification control areas based on the "vertical- and- horizontal" method, and provides reference for evaluating the impact of land use change on rocky desertification and improving the land use pattern in the study areas. The results show that: (1) Land use change in the rocky desertification control areas is evident. The proportion of land use change in Huajiang, Hongfenghu and Yachi is 2.85\%, 3.34\% and 37.88\%, respectively. Forest and construction land increased, while farmland and unused land decreased. (2) The comprehensive security and ecological, economic and social securities of land use change in different areas are different. The comprehensive security of Huajiang and Hongfenghu rose by $1.44 \%$ and $0.46 \%$, while that of Yachi declined by $1.9 \%$. In the Huajiang control area, the ecological and social securities were raised, and the economic security was declined. In the Hongfenghu control area, the ecological security rose, the economic security did not change remarkably, and the social security declined a little. In the Yachi control area, the ecological security declined significantly, the economic security rose a little, and the social security declined slightly. (3) The sensitivities of ecological, economic and social securities to land use change are different obviously, and ecological security is the most sensitive among these securities. The results reveal that the effect of land use change on ecological security is most obvious. In the follow- up rocky desertification control and land use planning, we should focus on the effect of land use change on ecological security.
\end{abstract}

Keywords: security; land use change; rocky desertification; "vertical-and-horizontal" method 